\title{
Emission Characteristics of Agricultural and Industrial Cellulosic Wastes Blended with Gasoline
}

\author{
S Oyelami $^{*}$, EO Olafimihan ${ }^{2}$, OB Okedere ${ }^{3}$ \\ ${ }^{1}$ Department of Mechanical Engineering, Osun State University, PMB 4494, Osogbo, Nigeria \\ ${ }^{2}$ Department of Mechanical Engineering, Ladoke Akintola University of Technology, PMB 4000, \\ Ogbomoso, Nigeria \\ ${ }^{3}$ Department of Chemical Engineering, Osun State University, PMB 4494, Osogbo, Nigeria \\ *Corresponding author: seun.oyelami@ uniosun.edu.ng
}

\section{Article History}

Received: September 09, 2020 Received in revised form: October 30, 2020 Accepted: November 01, 2020 Published Online: December 312020

\begin{abstract}
Agricultural and industrial wastes like sawdust and corncobs are definitely pollutants as they are disposed in dump sites and burnt in open air in most developing countries, like Nigeria. Proper utilization of these wastes could help reduce the environmental pollution arising from wastes disposal and combustion of fuels. Emissions generated from running an internal combustion (IC) engine with blends of gasoline and bio-ethanol produced from these wastes, as well as those of pure gasoline were compared in this work. A gas emission analyzer was placed at the exhaust of the IC engine and the readings were taken for each blend and for each round of testing period. The read out emissions were then compared with each other. The range of emissions for carbon monoxide (CO) were 1.45-2.75; 2.10-2.90; 2.00-2.62 and 3.0\% vol., for corncobs bio-ethanol/gasoline, softwood sawdust bio-ethanol/gasoline, hardwood sawdust bio-ethanol/gasoline and pure gasoline samples respectively while the emission ranges for hydrocarbon (HC) were 260-435; 328-360; 313-350 and 480 ppm for the same samples respectively. In the case of carbon dioxide (CO2), the samples gave 2.6-4.0; 2.2-3.9; 3.2-4.2 and $3.0 \%$ vol. emissions. Thus all stakeholders considering the adoption of fuel blends in the country's quest for increased energy mix can be properly guided on the pollutants associated with the investigated waste materials. This may help in the choice of appropriate waste to energy.
\end{abstract}

Keywords: waste, energy, emission, bio-ethanol, cellulosic

\subsection{INTRODUCTION}

Fossil fuel energy sources such as gasoline, coal and natural gases contribute to global warming and ozone layer depletion. Organic fuels apart from being renewable are also characterized by reduced emissions of greenhouse gases and can represent a very cheap alternative to gasoline which can effectively ameliorate the growing concerns of energy shortage [17]. Cellulosic wastes like corncobs are renewable agricultural resources, generation of bio fuels from such wastes is of importance for possible replacement of the conventional fuels [1] and [8]. Cellulosic biomass wastes are not properly managed in developing countries such as Nigeria and are therefore of great health and environmental risks [3]. Disposal of municipal solid waste, has become a great problem for both developed and developing [14]. As part of effects to improving environments and sourcing for low cost and sustainable alternative to gasoline. [21] and [12] explained that the content of ethanol is important for improving the burning process. The half-life of ethanol is reported to be between 6.5 and 26 hours in surface water. Degradation of the atmosphere is also expected to be swift [20]. Indian among other nations began bio-fuel technology that generate energy security, which made them the largest producer of jathropa oil [4]. Green house emission could be effectively tackled by embracing the use of biofuels, but it is also being seriously criticized because of the limitations of the bio-fuels produced from foods and feeds 
stocks called first generation bio-fuel, unlike the second generation bio-fuels produced from agricultural and industrial wastes.

Cellulosic ethanol is a major advantage in reducing emissions of greenhouse gas (GHG) by 85 percent over gasoline [15]. Rice at al [13] said that the atmospheric quality is improved by using higher ethanol in mixed fuel than pure gasoline. An increasing utilization of first-generation bio-fuels leads to an increase in the need for high quality land and fertilizer that is linked to global warming and can pollute groundwater. These organic fuel plants require more pesticides and decrease biodiversity since they are predominantly mono-cultural. In Brazil, in particular, substantial areas of tropical woodland are being burned to give way to such plants which release $\mathrm{CO} 2$ and cause soil erosion. [18] and [9] noted that the addition of ethanol does not have an impact on $\mathrm{CO} 2$ emissions, and [6] as well as the decrease in the amount of ethanol in [7].

Park et al [10] reported that mixed ethanol fuel rather than pure gasoline can reduce $\mathrm{CO} 2$ emissions. In addition, $\mathrm{CO} 2$ emissions were decreased by approximately 10 percent when mixed fuels were used by [2] [16] studied the effect of ethanol additives on gasoline and reported that ethanol generally produced a more controlled UHC motor output when using E90 and E100 fuel.

Currently, issues pertaining to land use are at the interface of climate change discussions, food sovereignty, indigenous rights, social and environmental justice. Probably the key issue is the competition for foodstuffs [19] and [15]. The purpose of this study is to investigate the use of non-food as feedstocks for ethanol production and subsequently as blend for fuel.

\subsection{METHODOLOGY}

The preparation of the feedstock involved the smashing and grinding of the Corncobs and Sawdust, to smaller particles size of $0.58 \mathrm{~mm}$, this was to enlarge the surface thus increasing the accessibility of acid into the feedstock. Saccharomyces cerevisiae was used in the fermentation process and cultivated for 48 hours prior to the experiment. Agar (PDA) sample $100 \mathrm{~g}$ was dissolved in a conical fiber entirely in $250 \mathrm{ml}$ water. The cotton and foil paper covered the mixture and sterilized for 15 minutes in the autoclave at 121 o $\mathrm{C}$. The content were allowed to cool, and then filled up to the brim with Saccharomyces cerevisiae by the help of sterilized inoculation loop. The content of the petri dishes were then sealed and maintained in an incubator at $25 \mathrm{oC}$ for 48 hours. The sample has been seen to produce particle uniformity. The moisture removal sample was then dried for 12 hours. In standard conditions, a 250ml beaker is filled with 100 g dry sample and $100 \mathrm{ml}$ with $18 \mathrm{M} \mathrm{H} 2 \mathrm{SO} 4$ (78\% w /v of acid).

The reaction was spontaneous in producing lignin, which was regarded as black residue However, the pH was maintained between 5.0-6.0 for optimal performance of Saccharomyces cerevisiae using $9 \mathrm{M} \mathrm{NaOH}$. The solution is filtered using a Buchner funnel to produce the cellulose substratum as residue. Saccharomycece cerevisiae was dissolved by $10 \mathrm{ml}$ distilled water containing between 80 and 20 drops in the agar slant tube. Agar slant tube is a screw-capped culture tube partly filled with an agar mix such as nutrient agar. In making it a slat tube, the agar is allowed to cool with the tube laying at an angle, resulting in a large surface area for spreading a culture. Then the cellulose substrate was added to ferment 10 $\mathrm{ml}$ of the solution. The mixture was poured in the distilled water for dilution and not vice versa to avoid a natural inclination, so to have a much smaller, safer scale. Sugar content of the sample was tested four-hourly to determine the rate of sugar conversion to ethanol as well as fermentation period and fermentation rate. Ethanol was fermented for 4862 hours at $300 \mathrm{C}$ in a shaker incubator of $150 \mathrm{rpm}$ to enable full fermentation. The fermented beer was later sieved to have the fluid. The fermentation process was conducted at room temperature. Fluid then pass through another stage of purification by the use of the distillation bath which was monitored, to have the product at 78.50C, the actual boiling point of ethanol. The block diagram showing the hydrolysis and fermentation steps is as shown in figure 1 and the properties of the ethanol produced and that of pure gasoline are as summarised in Table $1 .$. 


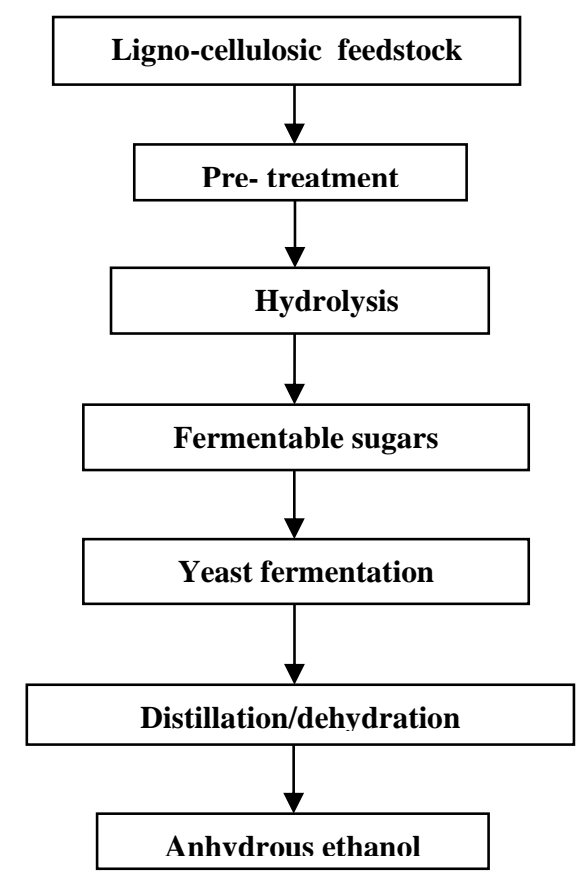

Figure 1: Process flow diagram of Bio-ethanol Production Process of Ligno-cellulosic Feedstock.

Table 1 Properties of ethanol produced from feedstocks

\begin{tabular}{|c|c|c|c|c|}
\hline Parameters & $\begin{array}{c}\text { Gasoline/ } \\
\text { Gasoline } \\
\text { (Yucesu,et } \\
\text { al,2006) }\end{array}$ & $\begin{array}{l}\text { Corncob } \\
\text { Ethanol }\end{array}$ & $\begin{array}{c}\text { Sawdust } \\
\text { (Softwood) } \\
\text { Ethanol }\end{array}$ & $\begin{array}{c}\text { Sawdust } \\
\text { (Hardwood) } \\
\text { Ethanol }\end{array}$ \\
\hline Colour & & Colourless & Colourless & Colourless \\
\hline Density $\left(\mathrm{g} / \mathrm{cm}^{3}\right)$ & $0.69-0.79$ & 0.8158 & 0.7898 & 0.7876 \\
\hline Purity (\%) & 100 & 95.68 & 99.59 & 99.90 \\
\hline Flash point $\left({ }^{\circ} \mathrm{c}\right)$ & 22 & 17 & 14 & 14 \\
\hline Pour point $\left({ }^{\circ} \mathrm{c}\right)$ & 32 to -57 & -5 & -5 & -5 \\
\hline Fire point $\left({ }^{\circ} \mathrm{c}\right)$ & 43 & 44 & 48 & 47 \\
\hline $\begin{array}{c}\text { Vapour } \\
\text { Pressure }(\mathrm{kPa}) \\
\end{array}$ & $7-9$ & 5.32 & 5.74 & 5.72 \\
\hline Octane Number & $88-100$ & 108.6 & 108.6 & 108.6 \\
\hline Hydrogen (\%) & $12-15$ & 8.0 & 13.0 & 10.0 \\
\hline Carbon (\%) & $85-88$ & 75.3 & 76.4 & 75.8 \\
\hline
\end{tabular}

The small Test Engine (TD200), a four-stroke engine, was set to an idle speed not below 1300 revolutions per minute $(\mathrm{rpm})$, the starting speed for the tests. For a while the engine could operate at that speed to warm it up to a uniform temperature. Preliminary controls were made with $500 \mathrm{ml}$ of gasoline to ensure the engine could work smoothly without hitch. The first desired speed of $2000 \mathrm{rpm}$, measured using a tachometer, was driven by the engine. The time 
needed for the consumption of $24 \mathrm{ml}$ of fuel was read by using the stop clock, and the frequency of the brake and the load of balancing were also observed. The dynamometer load was gradually increased until zero read spring balance, the charge was observed. The versatile data acquisition system (VDAS) software that was installed on a computer and connected to the VDAS hardware through a wired connection was used in recording the required data at this speed at $2200 \mathrm{rpm}, 2400 \mathrm{rpm}, 2800 \mathrm{rpm}$ and $2600 \mathrm{rpm}$, for E3.5, E7.0,

E10.5 and E14 respectively. E3.5, E7.0, E10.5 and E14.0 represent 3.5\%, 7.0\%, 10.5\% and 14\% of bio-ethanol in gasoline as respectively. The emission compositions $(\mathrm{CO} 2, \mathrm{CO}, \mathrm{HC})$ for each proportion of the blends were recorded by setting up a portable gas analyzer of model 900403 from Bridge Analyzers, Inc. 5198 Richmond Rd, Bedford Heights, OH 44146, United States. The experimental set up is as shown in Figure 2.

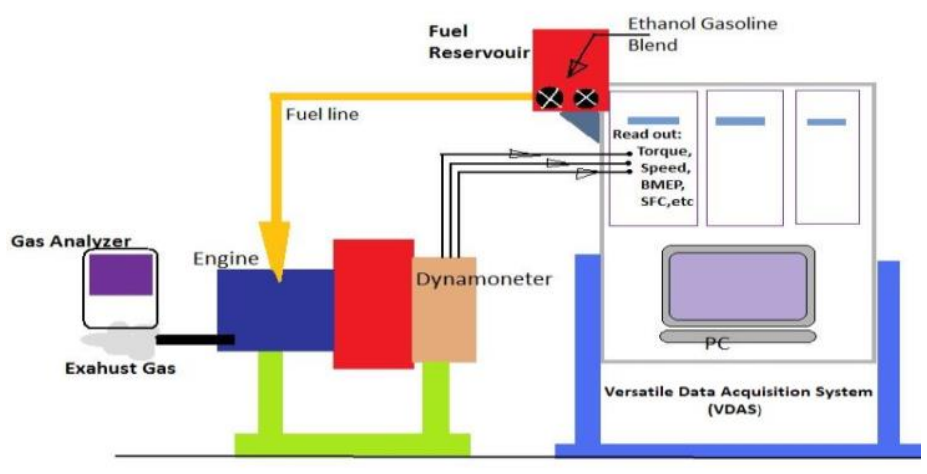

Figure 2: Engine, dynamometer and instrumentation unit.

\subsection{RESULTS AND DISCUSSION}

The emission from running the various (fuel blends) samples labelled X (corncobs bioethanol/gasoline), Y (softwood sawdust bioethanol/gasoline) and Z (hardwood sawdust bioethanol/gasoline) was plotted alongside that of pure gasoline in the small test engine (TD200), a four-stroke internal combustion engine having its exhaust connected to the gas emission analyser shown in figure 3, for comparison. The range of emissions for CO were 1.45-2.75; 2.10-2.90; 2.002.62 and $3.0 \%$ vol., for corncobs bio-ethanol/gasoline, softwood sawdust bio-ethanol/gasoline, hardwood sawdust bioethanol/gasoline and pure gasoline samples respectively while the emission ranges for HC were 260-435; 328-360; 313350 and $480 \mathrm{ppm}$ for the same samples respectively. In the case of CO2, the samples gave 2.6-4.0; 2.2-3.9; 3.2-4.2 and $3.0 \%$ vol. emissions as shown in Figures 3, 4 and 5 respectively.

The emission results of $\mathrm{CO}, \mathrm{HC}$ and $\mathrm{CO} 2$ for the tested blend ratios compared to that of pure gasoline are as shown in Figures 3 to 5 below. Figure 3, shows that, because of the leaning effect caused by the addition of ethanol, CO emissions decreased drastically compared to E0, which has a highest number of 3.1. CO as a toxic gas is caused by incomplete combustion; the combustion process in the engine is improved when the ethanol containing is blended with gasoline. The hydroxyl group $(\mathrm{OH})$ releases oxygen to aid oxidation thus resulting in complete combustion and $\mathrm{CO}$ formation is reduced. In the first sample, E10.5 for the second sample and E10.5 for the third sample, the minimum CO was obtained. $\mathrm{CO}$ at E14 blend shows emission reduction of 53.22\%, $12.58 \%$ and $27.74 \%$ for corncobs, softwood sawdust and hardwood sawdust respectively. Figure 4, depicts that $\mathrm{HC}$ emission decreases in the blends for all samples compared to E0 which has highest emission of 480. Ethanol can reduce the total output of hydrocarbon emissions, according to the results. The reason for this is similar to the behaviour of hydroxyl $(\mathrm{OH})$ group in ethanol as more oxygen is available for complete combustions of unburnt hydrocarbons. At E14, HC emission was reduced to the tune of $20 \%, 31.04 \%$ and $27.08 \%$ for corncobs, softwood sawdust and hardwood sawdust respectively.

Figure 5, depicts that $\mathrm{CO} 2$ emission increases in other blends compare to E0, except for E7.0 and E10.5 in the first and second sample respectively. The combustion process is more end to end and the $\mathrm{CO} 2$ emission concentration higher when the engine condition is learned. The $\mathrm{CO} 2$ emissions results were expected to be close or higher because of the high content of oxygen in bio-ethanol is expected to aid complete combustion, at E14, the result shows increase of $23.33 \%, 3.33 \%$ and $6.7 \%$ for corncobs, softwood sawdust and hardwood sawdust respectively. In comparison to pure gasoline, on average, the emission is better at blending as compared to other researchers conclusions [11] and [5]. The comparison of the samples shows that on the average emission is even better off using the sample $\mathrm{X}$. 


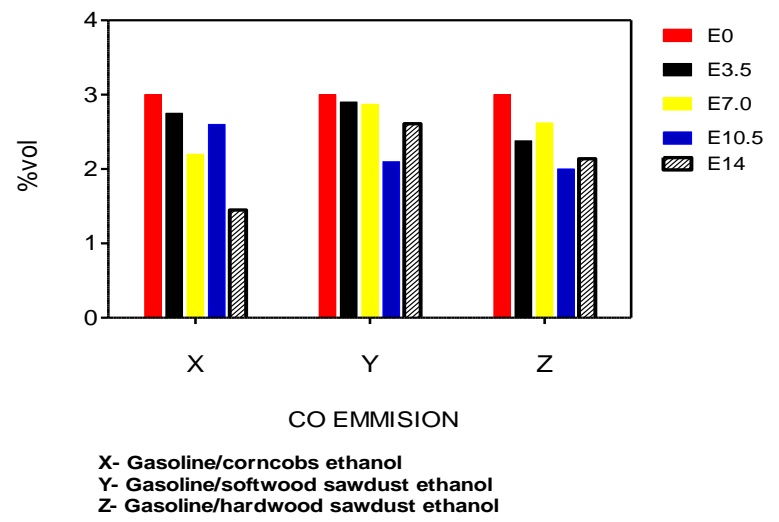

Figure 3: CO Emission Result for Blends of the Samples

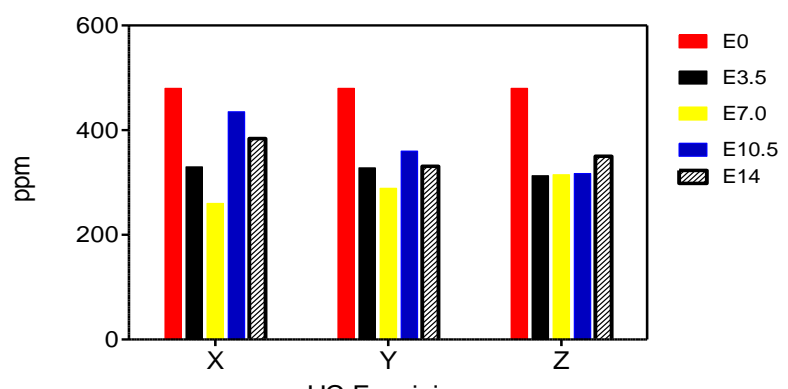

HC Emmision

X- Gasoline/corncobs ethanol

Y- Gasoline/softwood sawdust ethanol

Figure 4: HC Emission Result for Blends of the Samples

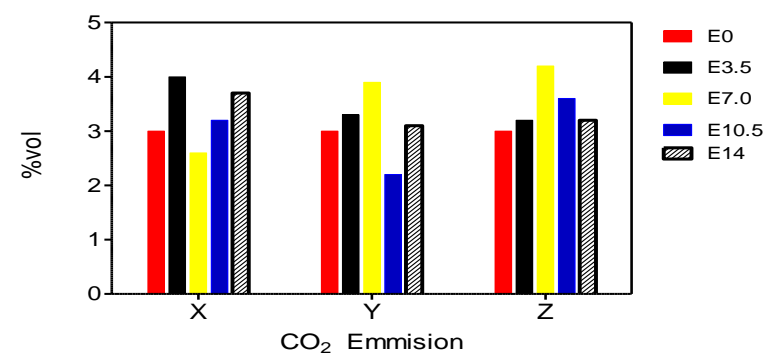

X- Gasoline/corncobs ethanol

Y- Gasoline/softwood sawdust ethanol

Figure 5: $\mathrm{CO}_{2}$ Emission Result for Blends of the Samples

\subsection{CONCLUSION}

The emission characteristics of bio-ethanol/gasoline blends using second generation feedstocks have been investigated in this work. Second generation bio-fuels produced from agricultural and industrial wastes is obviously a way to go in tackling most environmental challenges surrounding both wastes as well as emissions from fuels. Results from this study showed that emissions were generally lower with the blends as fuel than when pure gasoline was used. The major reason for this is the release of additional oxygen from the hydroxyl group of the bio-ethanol which aided the complete combustion. Among the blends, corncobs bioethanol/gasoline, on the average has shown to be more effective with maximum sustainable environmental effects in terms of pollution. 


\section{References}

[1] Adebayo A. and O. Awogbemi. 2017. Effects of Fuel Additives on Performance and Emission Characteristics of Spark Ignition Engine. European Journal of Engineering Research and Science, 2(3): 30-35. DOI:https://doi.org/10.24018/ejers.2017.2.3.289

[2] Agarwal, A., 2007. Bio-fuels (alcohols and biodiesel) applications as fuels for internal combustion engines, Progress in Energy and Combustion Science. 33: 233-71

[3] Akowuah, J., F. Kemausuor, and S. Mitchual. 2012. Physico-Chemical Characteristics and Market Potential of Sawdust Charcoal Briquette, International Journal of Energy and Environmental Engineering, 3: 20.

[4] Blanchard, R., S. Bhattacharya, M. Chowdhury, B. Chowdhury, K. Biswas, and B. Choudhury. 2015. A review of bio-fuels in India: challenges and opportunities. Presented at World Energy Engineering Congress, Orlando, Florida, USA.

[5] Florinda M., F. Carlos S. Miroslava and C. Nídia. 2019.Analysis of Fossil Fuel Energy Consumption and Environmental Impacts in European Countries. Energies, 12: 964

[6] Guerrieri, D., P. Caffrey, and V. Rao. 1995. Investigation into the Vehicle Exhaust Emissions of High Percentage Ethanol Blends, SAE, 85-95.

[7] Juan E., I. José, O. Sebastián, F. Luis and E. José. 2018. The effect of using ethanol-gasoline blends on the mechanical, energy and environmental Energies, Vol. 11, pp.221; doi:10.3390 www.mdpi.com/journal/energies

[8] Mehmet I. I, T. Selim, O. A. Selahaddin and K. Nafiz. 2019. Alternative Fuels for Internal Combustion Engines, Intechopen, 85446, DOI: 10.5772

[9] Najafi, G., B. Ghobadian, A. Moosavian, T. Yusaf, R. Mamat, M. Kettner, W. Azmi. 2016. SVM and ANFIS for prediction of performance and exhaust emissions of a SI engine with gasoline-ethanol blended fuels. Applied Thermal Engineering, 95: 186-203.

[10] Park, C. Y. Choi, C. Kim, S. Oh, G. Lim, and Y. Moriyoshi. 2010. Performance and exhaust emission characteristics of a spark ignition engine using ethanol and ethanol-reformed gas, Fuel, 89: 2118-2125.

[11] Pourkhesalian, A. A. Shamekhi and F. Salimi. 2010. Alternative fuel and gasoline in an SI engine: A comparative study of performance and emissions characteristics, Fuel, 89: 1056-1063.

[12] Ragland, K.W., D.J. Aerts, and A.J. Baker. 1991. Properties of Wood for Combustion Analysis, Bioresource Technology 37: $161-168$.

[13] Rice, R., A. Sanyal, A. Elrod, and Bata, R. 1991. Exhaust gas emissions of butanol, ethanol and methanol-gasoline blends, Journal of Engineering for Gas Turbine and Power, 11: 337-381.

[14] Shruti A. Byadgi and P. Kalburgi. 2016. Production of Bio-ethanol from waste newspaper. Procedia Environmental Sciences 35: 555 - 562

[15] Somma D., H. Lobkowicz and J., Deason. 2010. "Growing America's fuel: an analysis of corn and cellulosic ethanol feasibility in the United States" (PDF). Clean Technologies and Environmental Policy. 12 (4): 373-380.

[16] Song, C., W. Zhang, Y. Pei, G. Fan, and G., Xu. 2005. Comparative effects of MTBE and ethanol additions into gasoline on exhaust emissions, Athmospheric Environment, 40: 1957-1970.

[17] Srithar K., K.A. Balasubramanianb, V. Pavendana, B.A. Kumar. 2014. Experimental investigations on mixing of two biodiesels blended with diesel as alternative fuel for diesel engines. Journal of King Saud University - Engineering Sciences. 29(1): 50-56

[18] Stephen S. and R. David. 2018. Impact of ethanol blending on particulate emissions from a spark-ignition direct-injection engine. Fuel, 236: 1548-1558. https://doi.org/10.1016/j

[19] Temper, L., J. Martinez-Alier, 2012. Mapping resistance and resilience to the global landgrab: definitions, financial activism and alliances. Paper presented at the conference on 'Global Land Grabbing II', Cornell University, Ithaca.

[20] Wang M., C. Saricks D.Santini. 1999. Effects of fuel ethanol use on fuel cycle energy and greenhouse gas emissions. Argonne (IL): Argonne National Laboratory.

21] Wu, C. R. Chen, J. Pu, J. and Lin, T., 2004. The influence of air-fuel ratio on engine performance and pollutant emission of an SI engine using ethanol-gasoline blended fuels, Atmospheric Environment, 38(40): 7093-7100. 